\title{
Marijuana Odor Perception: Studies Modeled From Probable Cause Cases
}

\author{
Richard L. Doty,,$^{1,3}$ Thomas Wudarski,' David A. Marshall, ${ }^{1,2}$ \\ and Lloyd Hastings ${ }^{1}$
}

The 4th Amendment of the United States Constitution protects American citizens against unreasonable search and seizure without probable cause. Although law enforcement officials routinely rely solely on the sense of smell to justify probable cause when entering vehicles and dwellings to search for illicit drugs, the accuracy of their perception in this regard has rarely been questioned and, to our knowledge, never tested. In this paper, we present data from two empirical studies based upon actual legal cases in which the odor of marijuana was used as probable cause for search. In the first, we simulated a situation in which, during a routine traffic stop, the odor of packaged marijuana located in the trunk of an automobile was said to be detected through the driver's window. In the second, we investigated a report that marijuana odor was discernable from a considerable distance from the chimney effluence of diesel exhaust emanating from an illicit California grow room. Our findings suggest that the odor of marijuana was not reliably discernable by persons with an excellent sense of smell in either case. These studies are the first to examine the ability of humans to detect marijuana in simulated real-life situations encountered by law enforcement officials, and are particularly relevant to the issue of probable cause.

KEY WORDS: marijuana; psychophysics; law; olfaction; magnitude estimation.

The 4th Amendment of the United States Constitution protects American citizens against unreasonable search and seizure without probable cause. Probable cause for search occurs when known facts and circumstances of a reasonably trustworthy nature are sufficient to justify a person of reasonable caution and prudence in the belief that a crime has been or is being committed (Draper v. United States, 1959). Although this definition is common to most legal textbooks, the subjective nature of this justification can be problematic in practical application. This issue becomes

${ }^{'}$ Smell and Taste Center, University of Pennsylvania School of Medicine, Philadelphia, Pennsylvania. ${ }^{2}$ Dr. David A. Marshall is deceased.

${ }^{3}$ To whom correspondence should be addressed to Smell and Taste Center, University of Pennsylvania Medical Center, 5 Ravdin Building, 3400 Spruce Street, Philadelphia, Pennsylvania 19104; e-mail: doty@ mail.med.upenn.edu. 
particularly troubling when the sensory perception of weak stimuli, such as faint odors, is the basis for search.

Law enforcement officers often justify searches with their sense of smell when other more tangible criteria are not present. This type of encounter often occurs when the odor of marijuana (Cannabis sativa L.) is the basis for probable cause for entering vehicles and dwellings to search for illicit drugs (e.g., United States of America v. Boger, 1990; United States of America v. Ellis, 1998; United States of America v. Reilly, 1994; United States of America v. Shates, 1995). Unfortunately, little research exists on the human capacity to detect marijuana's odor in either laboratory or specific real-life situations, despite its widespread acceptance by law enforcement. This dearth of information bears considerable legal consequence, because courts often accept the argument, prima facie, that marijuana's odor can always be detected. In one instance, for example, police officers reported the smell of marijuana when a subsequent search revealed only cocaine (United States of America v. Harris, 1994). This case exemplifies the misappropriate use of smell for probable cause, and clearly illustrates a grave problem that must be addressed.

It is generally believed that the characteristic marijuana odor can be discerned from a wide variety of $C$. sativa plants, regardless of their geographic origin, strain, extent of processing, and tetrahydrocannabinol (THC) content. However, such beliefs are based largely on anecdote, and there is a disturbing absence of quantitative information on this topic. One study reports that all volatile oils prepared from freshly collected C. Sativa buds have a characteristic marijuana smell (Ross \& El Sohly, 1996), although no formal organoleptic investigation was made. It is not clear whether subtle differences exist in the smell of these oils, but it has been suggested that the essential oil of $C$. sativa may differ enough among geographic locations to serve as a chemical marker for general origin or type (Hemphill, Turner, \& Mahlberg, 1980). However, the considerable variability in the chemical composition of such volatiles among plants even from the same location may make such discernment extremely difficult, if not impossible (Hood \& Barry, 1978).

The present studies arose from the need to better understand the nature of marijuana's odor and whether humans can discern this odor in situations modeled from "real-life" law enforcement encounters. The first set of experiments investigated a situation in which the arresting officer reportedly discerned processed marijuana within an automobile trunk from the passenger compartment. In this work, we initially determined whether marijuana odor was discernible through the walls of the plastic bag containing the marijuana. Following confirmation of this point, we determined whether this discernment could occur inside the passenger's compartment of a car when the trunk contained the same packaged marijuana.

The second set of experiments was based upon a situation present in an illicit marijuana grow house in northern California. In the grow house, odors from immature Cannabis sativa plants were combined with diesel exhaust from a generator and expelled out through a chimney. Law enforcement officials reported being able to smell the marijuana from a road several hundred yards away, and subsequently used this odor as probable cause for a search. In this second set of studies, we first sought to determine whether the odor of immature marijuana plants differs in quality or intensity from that of mature marijuana plants. We then investigated whether participants 
were able to smell marijuana odor from a mixture emanating from immature $C$. sativa plants when combined with diesel engine exhaust. The ratio of marijuana odor to exhaust was modeled from the chimney effluence of the illicit California grow room.

\section{EXPERIMENT 1}

\section{Study 1}

The purpose of this study was to determine whether a group of men and women could distinguish the odor of packaged marijuana from that of a matched blank odor source.

\section{Methods}

Participants. Five men and four women recruited from advertisements placed on community bulletin boards served as participants. None reported being a smoker of marijuana, and all were nonusers of tobacco products. Most were in their " $20 \mathrm{~s}$ " (median $=27$ years) and all reported being in good general health. All were medication-free, and scored within normal limits on the University of Pennsylvania Smell Identification Test (UPSIT), a standardized olfactory test (Doty, 1995; Doty, Shaman, \& Dann, 1984).

Test Procedures. Prior to formal testing, the participants familiarized themselves with the odor of a sample of processed Mexican marijuana supplied by the New Jersey Attorney General's Office. A State law enforcement official was present during the testing and was custodian of the marijuana. Formal testing was performed in a $14 £ 17 \mathrm{ft}^{2}$ room with excellent air circulation. Each participant was blindfolded and led in one at a time at approximately 5-min intervals, at which point they were asked to sniff two garbage bags in succession ("Hefty" brand, 2-ply, 1.5 mil). One contained five 1-pound packets of pressed and processed Mexican marijuana and the other newspapers crushed and bundled in a similar fashion. Each participant was then required to report the bag that smelled most like marijuana. Half of the participants received the marijuana-containing bag first, so as to counterbalance test order.

\section{Results}

All nine participants reliably and unequivocally reported the garbage bag containing marijuana to have a marijuana-like smell, and none reported the control garbage bag as having such an odor (Binomial test, $p<.002$ ).

\section{Study 2}

The purpose of this study was to assess whether participants can reliably smell, from the driver's compartment of an automobile, the odor of the marijuanacontaining garbage bag housed in the trunk. 
Methods

Participants. The nine participants described in Experiment 1, who were now experienced in recognizing the odor of marijuana, participated in this study.

Test Procedures. This experiment was designed to simulate the conditions present when a 1983 2-door Chevrolet was searched for the presence of marijuana. Thus, the same automobile was provided by the State of New Jersey for this study, and the temperature at testing was only $0.6^{ \pm} \mathrm{C}$ different than on the day of the arrest. In the reallife situation, the estimated time that the marijuana had remained in the closed trunk prior to driving away from the procurement site was $20 \mathrm{~min}$, followed by $10 \mathrm{~min}$ within the trunk with the heater on and the windows shut.

In this study, four test sessions were conducted with either the marijuana or blank bag in the trunk compartment of the automobile. The bag was placed in the trunk for 20 $\mathrm{min}$, and then the automobile was driven for $10 \mathrm{~min}$. The automobile was then parked in the street where an experimenter monitored the participants and recorded their responses. This study was conducted double blind with neither the tester nor the participant knowing what was in the trunk. A technician was aware of which bag was placed in the trunk during each of the trials, and did not communicate this to anyone else involved until after the study.

During each of the four test sessions, the nine panel members were led individually at 2-min intervals to the driver's side of the automobile. The following instructions were then read to the participant: "When the driver gets out, sniff in the front seat area, and in the back seat area, and tell me if you smell the odor of marijuana. Tell me your response, yes or no, after you have finished sampling and the driver has gotten back into the car and closed the door." This process was repeated three times within each test session, providing a total of 27 trials per session. The participants were sequestered out of view of the automobile between trials, so they had no knowledge as to whether the odorant stimulus was changed or remained the same during the test session. After each session was completed, the stimulus bag was removed from the trunk and the trunk lid remained open for 5 min to permit airing out before the subsequent session.

\section{Results}

Six of the nine participants reported no marijuana odor being present on any of the six marijuana trials or any of the six nonmarijuana trials (Table 1). In aggregate the number of false positives $(9.26 \%$; 5 of 54 trials) was essentially the same as the number of correct positives (12.96\%; 7 of 54 trials). A one-tailed Fisher exact probability test revealed no meaningful difference between the hit and false positive rates $(p>.20)$.

\section{EXPERIMENT 2}

Experiment 2 was conducted in a state sanctioned medical Cannabis growing facility in Northern California. We first addressed whether nonbudding and budding 
Table 1. Hit and False Positive Rates for Identifying the Odor of Marijuana in Experiment 1, Study 2

\begin{tabular}{clll}
\hline Participant & Gender & Hit rate & False alarm rate \\
\hline 1 & Male & 0 of 6 & 0 of 6 \\
2 & Male & 0 of 6 & 0 of 6 \\
3 & Male & 0 of 6 & 0 of 6 \\
4 & Female & 0 of 6 & 0 of 6 \\
5 & Female & 0 of 6 & 0 of 6 \\
6 & Female & 0 of 6 & 0 of 6 \\
7 & Male & 2 of 6 & 3 of 6 \\
8 & Male & 1 of 6 & 0 of 6 \\
9 & Female & 4 of 6 & 2 of 6 \\
& Totals & 7 of 54 & 5 of 54 \\
\hline
\end{tabular}

marijuana plants produce similar odors. We then investigated if low levels of diesel exhaust fumes could mask the odor of immature marijuana plants.

\section{Study 1}

\section{Methods}

Participants. Five men and one woman, ranging in age from 20 to $57(M=41.5$ years, $S D=14.3$ ), served as participants. These individuals were recruited by word of mouth from the neighborhood surrounding the California grow facility, and all reported being in good general health. All exhibited above average smell function, as measured by the UPSIT (Doty, 1995; Doty, Shaman, \& Dann, 1984)

Stimuli and Test Procedures. The test stimuli consisted of four immature (nonbudding) female Cannabis plants, one mature (budding) female Cannabis plant, one female tomato plant (Lycopersicon), and one empty container containing planting soil. Only one mature Cannabis plant was used because the odor from this Cannabis plant was distinctive. Female plants were used because they produce more flower biomass than male plants, and are preferred by marijuana growers. Cannabinoids, such as 19tetrahydrocannabinal, tend to be particularly concentrated in the flowerrelated bracts (Turner, Hemphill, \& Mahlberg, 1980).

Polyethylene bags with no discernable odor were placed over each of the plants or the planting pot containing soil. The bags were positioned to collect the vapors emanating from the plant and associated potting soil. These vapors were sniffed by participants through a $20-\mathrm{cm}$ long, $2.54-\mathrm{cm}$ odorless PVC tube inserted through a slit in the bags. The temperature of the room in which testing occurred was $» 21^{ \pm} \mathrm{C}$.

Although all six participants indicated that they were aware of the smell of marijuana, we provided a sample to ensure familiarization with the odor. The participants were not informed of the positioning of the stimulus pots on the sampling table, and wore opaque goggles to preclude visual input.

Each participant was guided to the stimulus plant by an experimenter, who inserted the tube into the plant environs. The experimenter then positioned the participant's hands on the tube so as to enabling them to sniff through its end. The order of smelling the stimuli was systematically counterbalanced both between participants 
and within trial sessions of the same participant to preclude confounding by order effects. At least $45 \mathrm{~s}$ was interspersed between trials to minimize possible adaptation effects. The sniffing tubes were also cleaned with ethanol and water after use to eliminate any residual odors that accumulated during the test session.

The task of the participants was to report not only whether or not marijuana odor was present, but to quantitatively compare the relative intensity of the total odor using a magnitude estimation procedure. In this procedure odors are related relative to one another without a standardized scale (termed the free-modulus method). Because magnitude estimation numbers are ratio in nature, an assignment by a given participant of 25 to a stimulus theoretically is perceived half as intense as an assignment of 50. This method is well documented in the psychophysical and organoleptic sensory literature (Doty, 1975; Marks, 1988; Moskowitz, Dravnieks, Cain, \& Turk, 1974). The judgments were collected on three separate occasions, resulting in a total of 126 trials within the whole study. The median of the three intensity judgments for each participant was used as the intensity test measure.

Results

The identification data of the six participants revealed that: (i) the mature Cannabis plant was always rated as having a characteristic marijuana odor; (ii) three of the four immature Cannabis plants never were found to have a distinctive marijuana odor; (iii) one of the four immature Cannabis plants was always rated as having a marijuana-like smell; and (iv) the potting soil alone was always reported as having an odor, but never as having a marijuana-like odor.

The median magnitude estimates of the odor intensity for the potting soil, immature marijuana, mature marijuana, and tomato plant stimuli were calculated, and because magnitude estimation numbers are arguably ratio in nature, we determined ratios of the rated intensities relative to the baseline estimates of potting soil. These ratios are presented in Table 2.

Table 2. Magnitude Intensity Estimates Adjusted in Relation to the Intensity Estimates of Potting Soil for Participants in Study 1 of Experiment 2

\begin{tabular}{cccc}
\hline & \multicolumn{3}{c}{$\begin{array}{c}\text { Median odor intensity estimates in relation } \\
\text { to those of potting soil }\end{array}$} \\
\cline { 2 - 4 } & $\begin{array}{l}\text { Immature } \\
\text { Cannabis }\end{array}$ & $\begin{array}{l}\text { Mature } \\
\text { Cannabis }\end{array}$ & $\begin{array}{l}\text { Immature } \\
\text { Lycopersicon } \\
\text { (Tomato plant) }\end{array}$ \\
\hline 1 & 1.28 & 57.14 & 0.57 \\
2 & 2.00 & 10.00 & 2.00 \\
3 & 1.00 & 2.00 & 1.00 \\
4 & 0.97 & 1.11 & 0.69 \\
5 & 0.83 & 3.33 & 1.33 \\
6 & 2.00 & 5.00 & 1.50 \\
\hline
\end{tabular}

Note. For example, the first participant found the odor of immature marijuana to be 1.28 times more intense than the odor of potting soil alone, whereas the second found this odor to be two times more intense than that of the potting soil. 
It is clear from Table 2 that all six participants found the volatiles emanating from the mature marijuana plant to be more intense than the volatiles emanating from the immature marijuana plants or from the tomato plant. Statistical analysis using the nonparametric Wilcoxin matched-pairs signed ranks test revealed that volatiles emanating from the mature Cannabis plant were judged as having a significantly stronger odor than both the volatiles from the immature Cannabis plant and the tomato plant $(p<.025)$. Additionally, the intensities of the immature Cannabis plants did not differ significantly from the tomato plant.

\section{Study 2}

The purpose of Experiment 2 was to determine whether diesel exhaust odor could mask the odor of volatiles from Cannabis sativa L under a specific set of "realworld" circumstances. We aimed to conservatively model, within reasonable bounds, a situation present in the aforementioned California grow room where the exhaust of volatiles from immature Cannabis sativa plants were combined with diesel exhaust from a generator and expelled outside through a chimney. In effect, we sought to determine whether the odor of marijuana volatiles could be discerned from the background of diesel exhaust odor under conditions similar, or even more stringent, to those in this specific situation.

\section{Methods}

Participants. Five of the 10 participants in this experiment were the male participants of Study 1. One new participant was a female, and the other four new participants were male. The UPSIT was administered to three of these additional individuals and all were within normal limits. The remaining participants reported no problems smelling, although their sense of smell was not formally evaluated. Three of the five new participants reported having intimate knowledge of the smell of marijuana and admitted to being occasional or regular marijuana smokers.

Procedures. We employed an olfactometer capable of providing, for nasal sampling, a mixture of diesel exhaust and Cannabis volatiles in the relative proportions estimated to have been present within the chimney effluence of the illicit marijuana grow room (see Fig. 1). In this system, clean room air was pumped into two identical 114-1 galvanized steel chambers at a rate of $681 / \mathrm{min}$. In one of the 114-1 chambers, two marijuana plants ( $\gg 38 \mathrm{~cm}$ high) were situated; the other housed identical containers and potting soil, but no plants. To produce and maintain a temperature in these chambers equivalent to that present in the illicit grow room (approximately $27^{ \pm} \mathrm{C}$ ), digital temperature probes and 150-watt light bulbs were placed within them. The chamber temperatures were continuously monitored and the intensity of the light bulbs adjusted via a rheostat to maintain the temperatures at the desired level (range: $25^{ \pm}-28^{ \pm} \mathrm{C}$ ).

It should be noted that the two Cannabis plants employed in this study were selected from a larger number of similar plants available to us at the growing facility. We did not wish to bias the selection procedure, so none of these plants had been 


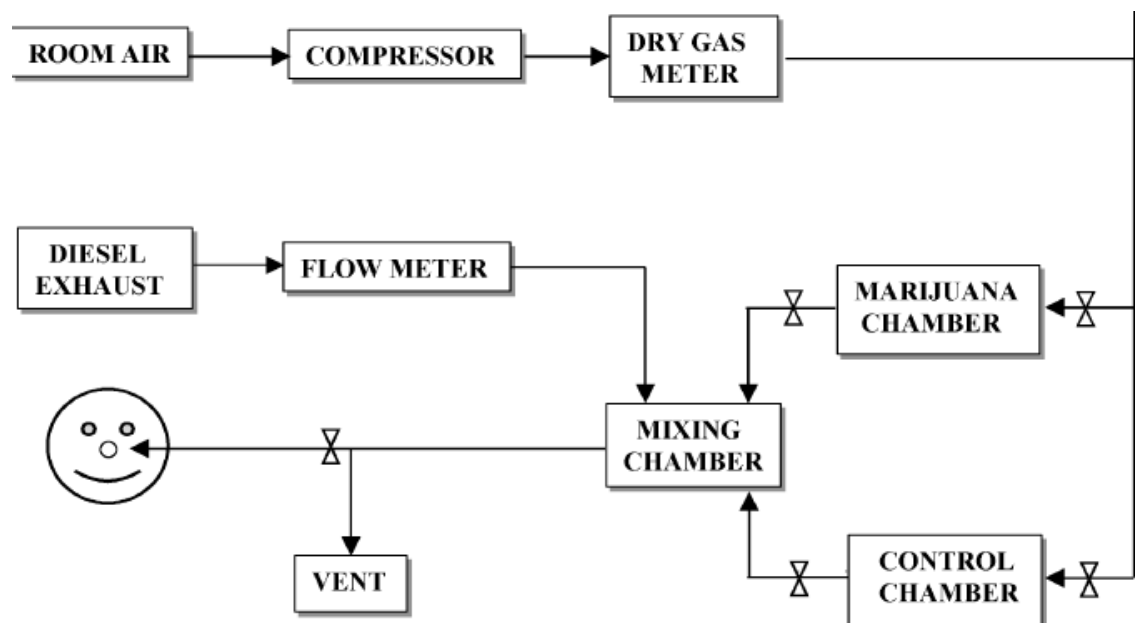

Fig. 1. Schematic diagram of olfactometer that allowed for mixing of diesel odor and marijuana volatiles for sampling by participants. signifies ball valves.

previously smelled. Each was assigned a number, and the two numbers chosen were determined using a random process.

The output of the olfactometer was channeled through a PVC pipe to a sampling port from which the participants made their observations. During the intertrial intervals, the test mixture was directed from the sniffing port. The basic parameters that had to be met or exceeded in the simulation were derived from measurements of the illicit California grow room and were as follows: (i): the volume of the air in the grow room $\left(190.5 \mathrm{~m}^{3}\right)$; (ii) the number of immature plants reportedly housed in the grow room (440); (iii) the air flow through the grow room (calculated at $65.14 \mathrm{l} / \mathrm{min}$ ); and (iv) the empirically determined flow rate of diesel engine exhaust $\left(3.8^{\mathrm{m} 3}\right.$ per minute at $\left.19^{ \pm} \mathrm{C}\right)$. The degree of dispersion of chimney effluent into the ambient air, which would dilute the effluent considerably and make detection even more difficult, was not included in the model.

In the original situation, one plant occupied $0.43 \mathrm{~m}^{3}$. However, the plants in the original illicit grow room were somewhat larger than those available to us for study. Therefore, because one plant originally occupied $0.43 \mathrm{~m}^{3}$, we placed two plants in the galvanized steel container (114 1). This provided a cushion of error to compensate for differences in plant density and any minor errors that may be present elsewhere in the model (e.g., differences between actual and measured flow rates). Additionally, a higher ratio of marijuana (or potting soil chamber) air to diesel exhaust effluent was employed to make even more conservative the test as to whether marijuana odor could be discerned within diesel exhaust.

The psychophysical paradigm consisted of 20 test trials given to 17 of the test participants. The number of trials of three participants was abbreviated because of schedule conflicts, resulting in 19 trials in two cases and 15 trials in the remaining case. In sum, 193 total trials were completed in the experiment. On half of the trials the diesel exhaust was presented with no marijuana odor (i.e., just the odor of potting 
soil), and on the other half the diesel exhaust was presented with the volatiles emitted from the marijuana plants and their potting soil. After switching the valves to a new test condition, 3-5 min were allowed to pass before testing commenced to insure adequate purging of the odors from the previous test condition.

The entire test session lasted approximately $3 \mathrm{hr}$. Each participant was tested individually and was instructed not to discuss his or her responses with the other participants. No information regarding the probability of a marijuana trial relative to a blank trial was provided. All participants received testing on a specific trial before the olfactometer was reset for the next trial. The task of each participant on each trial was to answer two basic questions: (i) do you smell diesel exhaust?; and (ii) do you smell marijuana odor?

\section{Results}

No convincing evidence was present in the data that any of the participants could reliably detect the marijuana odor embedded in the diesel fumes. A onesided Fisher exact probability test revealed no meaningful difference between the hit (6 of 96 trials) and false positive ( 3 of 96 trials) rates, implying that this level of responding to the diesel + marijuana vapor stimulus is within a range expected by chance. Hence, the data provided no statistical support for the notion that human participants can discern marijuana odor from diesel odor under the conditions of this experiment.

\section{GENERAL DISCUSSION}

In Experiment 1, we demonstrated that the odor arising from $2.5 \mathrm{~kg}$ of processed Mexican C. sativa is clearly discernable through a tightly sealed garbage bag sniffed at pointblank range. However, when the marijuana-containing garbage bag was placed in the trunk of an automobile under conditions analogous to those present in an actual search and seizure operation, there was no convincing evidence that the marijuana odor could be discerned.

In Experiment 2, we demonstrated that odors emanating from immature female marijuana plants are much less intense on average than odorous volatiles emanating from mature female marijuana plants. We also discovered no marijuana-like odor could be discerned in most immature marijuana plants. Consequently, participants were also unable to discern the odor of immature marijuana plants when they are mixed with diesel exhaust fumes in a ratio modeled from a real-life growing situation in an illicit California grow room. This failure to accurately discern marijuana was nearly absolute, with low false alarm and false positive rates. This presumably reflects, on the part of participants familiar with this odor, the expectation of a distinct marijuana smell that rarely, if ever, presented itself. A more liberal criterion, that is, a tendency to make both higher hit and false alarm rates, would be expected in persons who would have greater benefit in detecting the presence of marijuana, as might occur in some law enforcement situations.

These studies represent the first step in better understanding the nature of marijuana's odor and situations in which it can be perceived. However, these experiments 
are potentially limited to the rather specific conditions under which they were performed, and by the relatively small number of participants tested. Thus, their findings need not necessarily generalize to other, even seemingly similar, situations. For example, temperature is known to influence the release and diffusion of molecules from plant products. The inability to detect marijuana located in the trunk of a car from the driver's window may be different in on a hot summer day than under the winter conditions present in Experiment 1.

The participants of Experiment 1 had limited experience with marijuana odor, unlike the participants of Experiment 2. The degree to which use, or long-term experience with, marijuana-containing products on the ability of participants to recognize marijuana odor is unknown. In general, participants who are formally trained to recognize tastes and odors perform better on psychophysical tests, suggesting that training can alter some indices of performance (Smith, Doty, Burlingame, \& McKeown, 1993). The contention that law enforcement officers may be more accurate than laypersons in detecting marijuana by odor, however, requires substantiation. Other factors, including gender and age, may have a much more salient influence on the ability to smell and to detect marijuana at low concentrations (Doty et al., 1984). Just as with canines, standardized procedures are needed to establish the smell ability of law enforcement officers who are called on to testify about odors of elicit drugs.

Importantly, one must not overlook the fact that expectation or suggestion can often dictate the likelihood of a person believing that they smell an odor, a common problem in environmental annoyance issues. In the field of olfactory psychophysics, some participants report detecting odors even on blank trials (van Langenhove \& Schamp, 1989). This phenomenon is illustrated by a demonstration described by William James, the eminent nineteenth Century psychologist (James, 1890). Professor James told a classroom of students that he was about to open a small bottle with a very strong odor in it, and that they were to raise their hands when they first noticed the smell. A few minutes after removing the bottle top, students in the first rows of the lecture hall began raising their hands, and in a matter of minutes the whole room was filled with raised hands. In fact, the bottle had no discernible smell, containing only the vapors of water and a dying agent used to the make the water look dark!

The present findings throw into question, in two specific instances, the validity of observations made by law enforcement officers using the sense of smell to discern the presence of marijuana. Although these instances reflect a very small set of studies with very specific constraints, they do suggest that a blanket acceptance of testimony based upon reported detection of odors for probable cause is questionable and that empirical data to support or refute such testimony in specific cases is sorely needed.

\section{ACKNOWLEDGMENTS}

This work was supported, in part, by funds from the Attorney General's Office of the State of New Jersey and from the United States District Court, Northern District of California, San Francisco, California. 


\section{REFERENCES}

Doty, R. L. (1975). An examination of relationships between the pleasantness, intensity, and concentration of 10 odorous stimuli. Perception and Psychophysics, 17, 492-496.

Doty, R.L. (1995). The Smell Identification Test ${ }^{\mathrm{TM}}$ administration manual (3rd ed.). Haddon Heights, NJ: Sensonics, Inc.

Doty, R. L., Shaman, P., Applebaum, S. L., Giberson, R., Siksorski, L., \& Rosenberg, L. (1984). Smell identification ability: Changes with age. Science, 226, 1441-1443.

Doty, R. L., Shaman, P., \& Dann, M. (1984). Development of the University of Pennsylvania Smell Identification Test: A standardized microencapsulated test of olfactory function. Physiology and Behavior, $32,489-502$.

Draper v. United States, 358 U.S. 307, 79 S.Ct. 329, 3 L.Ed.2d 327 (1959).

Hemphill, J. K., Turner, J. C., \& Mahlberg, P. G. (1980). Cannabinoid content of individual plant organs from different geographical strains of Cannabis sativa L. Journal of Natural Products, 43, 112-122. Hood,

L. V. S., \& Barry, G. T. (1978). Headspace volatiles of marijuana and hashish: Gas chromatographic analysis of samples of different geographic origin. Journal of Chromatography, 166, 499-506. James,

W. (1890). Principles of psychology. New York: Holt.

Marks, L. E. (1988). Magnitude estimation and sensory matching. Perception and Psychophysics, 43, 511-525.

Moskowitz, H. R., Dravnieks, A., Cain, W. S., \& Turk, A. (1974). Standardized procedure for expressing odor intensity. Chemical Senses and Flavour, 1, 235-237.

Ross, S. A., \& El Sohly, M. A. (1996). The volatile oil composition of fresh and air-dried buds of Cannabis sativa. Journal of Natural Products, 59, 49-51.

Smith, R. S., Doty, R. L., Burlingame, G. K., \& McKeown, D. A. (1993). Smell and taste function in the visually impaired. Perception and Psychophysics, 53, 649-655.

Turner, J. C., Hemphill, J. K., \& Mahlberg, P. G. (1980). Trichomes and cannabinoid content of developing leaves and bracts of Cannabis sativa L. (Cannabaceae). American Journal of Botany, 67, 1397-1406. United States of America v. Ronald J. Boger, 755 F. Supp. 333 (1990). United States of America v. Deborah Ellis, 15 F. Supp. 2d 1025 (1998). United States v. Harris, 31 F.3d 153, 156 (4th Cir. 1994).

United States of America v. Keven C. Reilly, 875 F. Supp. 108 (1994). United

States of America v. Norris Shates, 915 F. Supp. 1483 (1995).

Van Langenhove, H., \& Schamp, N. (1989). Encyclopedia of environmental control technology (Vol. 2, pp. 935-963). Houson: Gulf Publishing. 